This document is the accepted manuscript version of the following article:

Spierings, A. B., Leinenbach, C., Kene1, C., \& Wegener, K. (2015). Processing of metal-diamond-composites using selective laser melting. Rapid Prototyping Journal, 21(2), 130-136. https://doi.org/10.1108/RPJ-11-2014-0156

\title{
PROCESSING OF METAL-DIAMOND-COMPOSITES USING SELECTIVE LASER MELTING
}

\author{
Adriaan Bernardus Spierings \\ Institute for Rapid Product Development, Inspire AG, St. Gallen, Switzerland \\ Christian Leinenbach \\ Laboratory for Joining Technologies and Corrosion, Empa, Swiss Federal Laboratories for Materials \\ Science and Technology, Dübendorf, Switzerland \\ Christoph Kenel \\ Laboratory for Joining Technologies and Corrosion, Empa, Swiss Federal Laboratories for Materials \\ Science and Technology, Dübendorf, Switzerland AND Institute of Machine Tools and Manufacturing, \\ ETH Zurich, Zurich, Switzerland, and \\ Konrad Wegener \\ Institute of Machine Tools and Manufacturing, ETH Zurich, Zurich, Switzerland
}

\begin{abstract}
$\underline{\text { Abstract }}$
Purpose

Powder-bed based additive manufacturing processes such as Selective Laser Melting (SLM) offer a huge degree of freedom, both in terms of part design and material options. In that respect, mixtures of different powders can offer new ways for the manufacture of materials with tailored properties for special applications such as metal-based cutting or grinding tools with incorporated hard phases. A feasibility study was performed to investigate the basic processability of a diamond-containing metal matrix.
\end{abstract}

\section{Design/methodology/approach}

A two-step approach was used to first investigate the basic SLM-processability of a Cu-Sn-Ti-Zr alloy, which is usually used for the active brazing of ceramics and superhard materials. After the identification of a suitable processing window, the processing parameters were then applied to a mixture of this matrix material with 10-20 vol.- $\%$ artificial, Ni-coated mono-crystalline diamonds.

\section{Findings, research limitations/implications,}

Even though the processing parameters were not yet optimized, stable specimens out of the matrix material could be produced. Also diamond containing mixtures with the matrix material resulted in stable specimens, where the diamonds survived the layerwise build process with the successive heat input, as almost no graphitisation was observed. The diamond particles are fully embedded in the $\mathrm{Cu}-$ $\mathrm{Sn}-\mathrm{Ti}-\mathrm{Zr}$ matrix material. The outer part of the diamonds partly dissolve in the matrix during the SLMprocess forming small $\mathrm{TiC}$ particles and most likely a thin $\mathrm{TiC}$ layer around the diamond particles.

\section{Originality/value}

The feasibility study approved the SLM-processing capabilities of a metal-diamond composite. Although some cracking phenomena sill occur, this seems to be an interesting and promising way to create new abrasive tools with added value in terms of internal and local lubrication supply, tooling temperature control and improved tooling durability.

Keywords: Selective Laser Melting, Hybrid materials, metal matrix composite, Diamonds, Microstructure 


\section{Introduction}

Additive manufacturing (AM) technologies offer many advantages for the tool-less production of highly complex parts directly from CAD data. Powder-bed-based processes - such as the selective laser melting (SLM) process - allow the production of parts in a wide range of metallic materials. The cross-sections of the parts to be built are thereby selectively scanned into thin layers of powder material using a high-power Nd-YAG laser source. There is a wide range of processable standard metal materials available. Stainless and hot-work steel (Averyanova and Bertrand, 2010; Spierings et al., 2011), aluminium (Berkau, 2011; Brandl et al., 2012; Buchbinder et al., 2011), titanium (Murr et al., 2009) and Ni-based materials (Mumtaz et al., 2008; Rickenbacher et al., 2013) are typical metal classes. Consequently, such parts can be used in a wide field of industrial applications: From tooling industry, lightweight structures for automotive and aerospace, functionally optimized parts for diverse industrial and customized implants and instruments for medical applications. A special field of application is the abrasive tooling industry, e.g. for grinding or cutting applications. They require materials with a special set of properties such as high wear resistance, good thermal conductivity, high material hardness and good chemical resistance. To fulfill and optimize these properties, measures can be taken on the material level and/or in structural optimizations of the tool itself, e.g. by incorporation of internal channels for local lubrication supply or tool cooling. Besides the advantage of AM for the manufacturing of complex-shaped metallic parts, this powderbased process offers a further potential for the creation of new materials, e.g. metal matrix composites (MMC), with improved and tailored properties. Applying these potentials of AM (SLM) in the tooling industry would therefore create a further potential to optimize tool durability both by tailored material properties (high thermal conductivity) and the incorporation of cooling channels and a local lubrication supply into the tools.

A good overview to currently used MMC materials is given by Richardson et al., 2013, pointing out that mainly Ni- or Co-bonded WC is used by the manufacturing industry. Ding et al. (2013) created single layers of brazed polycrystalline $\mathrm{CBN}$ particles on abrasive wheels using an active $\mathrm{Cu}-\mathrm{Sn}$-Ti brazing alloy. As the formation of AlN, TiN, TiB2, TiB and TiAl3 conforms to the chemical combination of polycrystalline $\mathrm{CBN}$ grains and the matrix material, good bonding of the diamond particles was achieved. Besides conventional MMC materials, diamondcontaining surface coatings offer also interesting possibilities. In many cases, such coatings are produced today by electrochemical deposition methods. Buhl et al. (2012) used an active brazing alloy to bond diamond particles onto a steel substrate for grinding applications. In contrast, Kovalenko et al. (2007) created single layers of steel and nickel-bonded synthetic diamonds (with additional hard phases in the matrix material) on a steel substrate using a highpower CO2 laser. The very short interaction time of the laser beam with the diamond particles combined with the very high heating and cooling rates resulted in no thermal destruction of the diamonds, except for those with initial defects.

An interesting, alternative way to such new materials is the processing of mixtures of different powders, where specific hard phases are mixed with a metallic matrix material. Based on mentioned initial results, the SLM process seems to be well-suited for the creation of metaldiamond composite materials. It can be expected that the high heating and cooling rates are at least similar to the ones of Kovalenko. An important difference, however, is the cyclic heating impact on diamond particles due to the layer-wise build process, which basically supports the tendency of diamond to graphitize. As natural diamond is known to graphitize at temperatures between about $1,500^{\circ} \mathrm{C}$ in an inert atmosphere or vacuum and about $1,000^{\circ} \mathrm{C}$ in normal air or in diamond-metal composites (Rabinkin et al., 2013), a limitation of the melting temperature of the matrix material to values below about $1,000^{\circ} \mathrm{C}$ is beneficial. Temperatures above might also be acceptable because the graphitization process is slow, whereas the heating cycle is very 
short. To limit the melting temperature, a $\mathrm{Cu}-\mathrm{Sn}-\mathrm{Ti}-\mathrm{Zr}$ active brazing alloy with a comparably low melting point was selected. Such active brazing alloys are typical brazing filler materials to join diamonds to metals and ceramics, respectively.

To investigate the basic processability of metal-diamond composites by SLM, a feasibility study was performed using a mixture of $\mathrm{Ni}$-coated natural diamond particles and the mentioned brazing alloy. This material combination is especially interesting for tooling applications, as the brazing alloy offers already a very high thermal conductivity, which might be even improved by the incorporation of diamond particles. In addition, a diamond-containing matrix material might also improve tool durability compared to the use of diamond-containing tool coatings.

The first results indicate that almost no graphitization of the diamond particles takes place during the successive heat input by the selective laser scanning process. Therefore, the diamond particles survive the SLM build process. The diamond particles are well-bonded to the matrix material most probably due to the creation of a thin TiC interconnecting layer between the diamond particles and the matrix material. However, cracking phenomena in the matrix are resulting from either the different thermal expansion coefficients of the brazing alloy and the diamond particles and a not-yet optimized alloy chemistry before the processing conditions of the SLM process. Therefore, a reduced Ti content would most probably sufficiently increase ductility of the matrix material. Nevertheless, the SLM processing of metal-diamond composites seems to be an interesting and promising way to create new abrasive tools with added value in terms of internal and local lubrication supply, tooling temperature control and improved tooling durability.

\section{Materials}

\section{Matrix material}

The matrix material is a $\mathrm{Cu}-\mathrm{Sn}-\mathrm{Ti}-\mathrm{Zr}$ active brazing alloy with the composition according to Table I. This alloy has been chosen for its beneficial thermal properties and high strength (Rp $=550 \mathrm{MPa}$ and $\mathrm{Rm}=820 \mathrm{MPa}$ ). Furthermore, Buhl et al. (2012) have successfully used this alloy to braze diamond particles on a steel substrate, achieving good bonding between the diamonds and the matrix material. This good bonding is due the 10 weight per cent content of titanium (and $\mathrm{Zr}$ ) in the alloy, forming very stable and uniform epitaxial TiC layers at the interface between the brazing alloy and the diamond particles, as pointed out by Rabinkin et al. (2013). According to the thermodynamic calculations by Wang et al. (2011), the selected ternary $\mathrm{Cu}-\mathrm{Sn}-\mathrm{Ti}-\mathrm{Zr}$ system has a liquidus temperature of $925^{\circ} \mathrm{C}$ and a solidus temperature of $868^{\circ} \mathrm{C}$. This is significantly lower than typical $\mathrm{Fe}-$, $\mathrm{Ni}$ - or other alloys, thereby improving thermal stability of the embedded diamond particles during SLM processing. In addition, the thermal conductivity of a $\mathrm{Cu}-\mathrm{Sn}$ alloy is much higher than for other alloys. The Copper Alliance (Kupferinstitut, 2005) published for a Cu-Sn12 alloy a thermal conductivity of _55 $\mathrm{W}(\mathrm{mK}) \_1$ at $20^{\circ} \mathrm{C}$ with a significant increase for higher temperatures. Even though an addition of Ti reduces the thermal conductivity somewhat, it is still much higher than, e.g., an Ni alloy. This high conductivity supports the need for an as short thermal impact on the diamond particles as possible, thereby reducing the risk of graphitization.

Table 1: Composition (wt.\%) of the active brazing alloy "Diabraze"

\begin{tabular}{c|c|c|c|c}
\hline Composition & $\mathrm{Cu}$ & $\mathrm{Sn}$ & $\mathrm{Ti}$ & $\mathrm{Zr}$ \\
\hline wt. $\%$ & 73.9 & 14.4 & 10.2 & 1.5 \\
\hline
\end{tabular}

the brazing alloy is available as a powder from spherical particles (Figure 1, left). The particle size distribution is $\mathrm{D}_{10}=7.6 \mu \mathrm{m}, \mathrm{D}_{50}=20 \mu \mathrm{m}$ and $\mathrm{D}_{90}=38 \mu \mathrm{m}$ (optically evaluated using the 

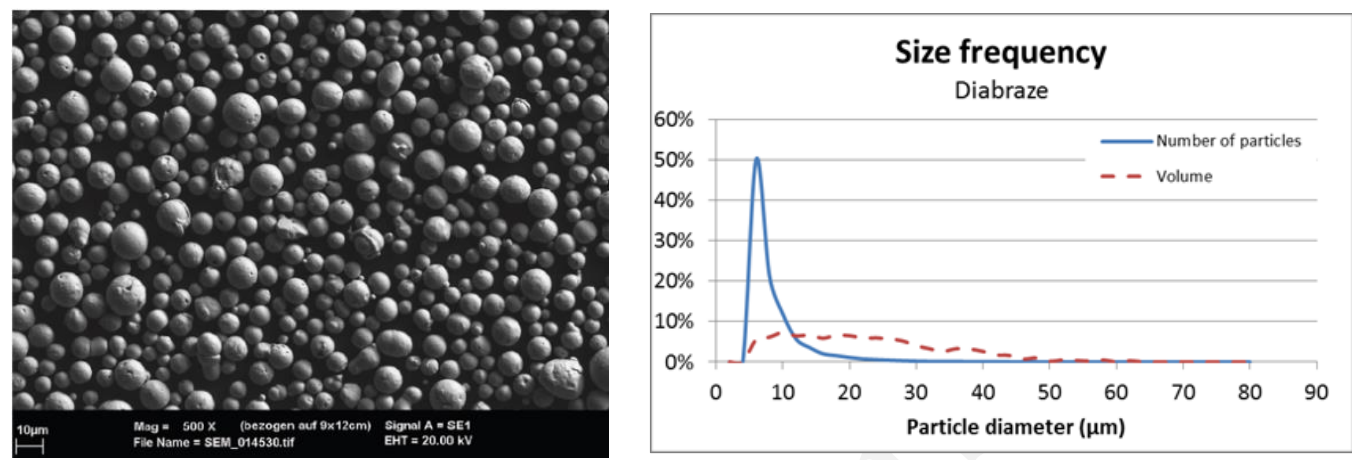

Figure 1: SEM of the Diabraze powder material and particle size distribution

\section{Diamond particles}

The abrasive powder material that is mixed with the matrix material are $\mathrm{Ni}$-coated diamond particles, where the Ni coating accounts for 50 volume per cent (Figure 2) of the particles. The selection of Ni-coated diamonds should improve the thermal stability of the diamond cores during SLM processing by forming a kind of a protective shield. The diamond particles were measured and evaluated using the PowderShape software with regard to the particle size distribution and their shape parameters. Depending on the particle model, their sizes are $33.9 \mu \mathrm{m} \pm 6.4 \mu \mathrm{m}$ (cross-sectional area equal to circles) or $43.9 \mu \mathrm{m} \pm 9.4 \mathrm{~m} \mu$ (biggest dimension of a particle), respectively. Their shape parameters are a convexity of $0.888 \pm 0.03$ and a Ferret ratio of $0.71 \pm 0.11$. This will enable an abrasive effect for those particles that are embedded in the surface of a tool. Mixtures of 10 and 20 volume per cent of $\mathrm{Ni}$-coated diamond particles and the brazing alloy were created by manually mixing the corresponding powders.
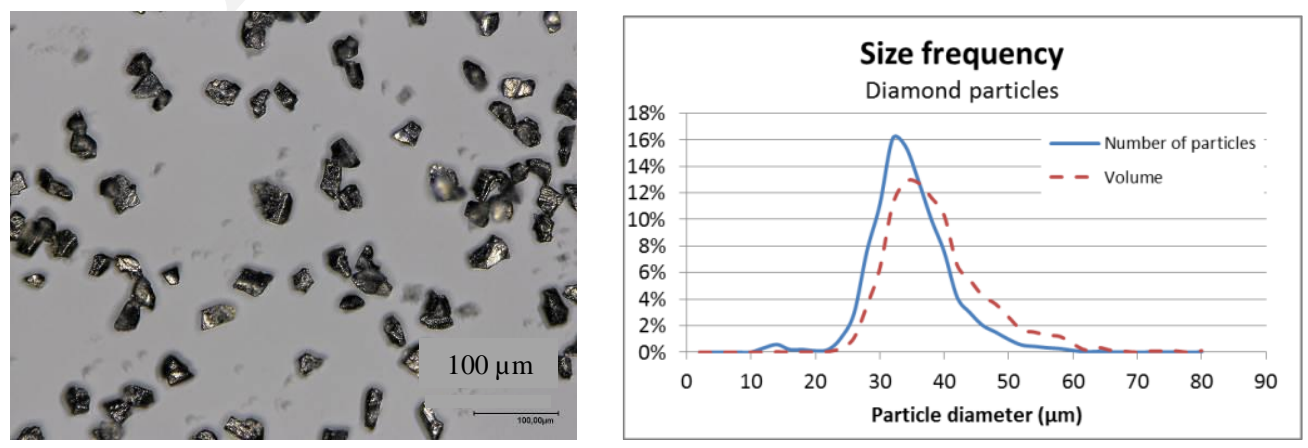

Figure 2: Diamond-Ni particles and corresponding particle size distribution.

Depending on the particle model, their sizes are $33.9 \pm 6.4 \mu \mathrm{m}$ (cross-sectional area equal to circles) or $43.9 \pm 9.4 \mu \mathrm{m}$ (biggest dimension of a particle), respectively. Their shape parameters are a convexity of $0.888 \pm 0.03$ and a Ferret ratio of $0.71 \pm 0.11$. This will enable an abrasive effect for those particles that are embedded in the surface of a tool. Mixtures of 10 vol- $\%$ and 20 vol- $\%$ of Ni-coated diamond particles and the brazing alloy were created by manually mixing the corresponding powders. 


\section{Experimental Methods}

$\underline{\text { SLM Machine }}$

A SLM machine type ConceptLaser M1 was used, which is equipped with a Nd:YAG disk laser having a maximal laser power of $100 \mathrm{~W}$ at the build platform and a laser spot diameter of about $0.2 \mathrm{~mm}$. The scan strategy used to produce the $10 \mathrm{x} 10 \mathrm{x} 7 \mathrm{~mm}^{3}$ test samples is unidirectional scanning, where the scan direction was turned by $90^{\circ}$ for each layer. This scan strategy is close to the standard scan strategy used on ConceptLaser machines. The uni-directional scanning was applied instead of meander scanning in order to minimize heat concentration effects at the turning points of the scan vectors.

Processing of the active brazing alloy alone

To investigate a possible processing window for the Diabraze matrix material, several different parameter combinations were performed using the ranges given in Table II, producing test cubes with a cross-section of $10 \times 10 \mathrm{~mm}^{2}$ and a height between $5 \mathrm{~mm}$ and $7 \mathrm{~mm}$. For some samples, the layers were scanned twice with the aim of increasing the density at a lower laser energy input. The general aim was to reach qualitatively good samples without break-outs and with a high matrix material density. Processing was performed in protective atmosphere using argon. Builds were created on a steel platform, offering sufficient bonding between the brazing alloy and the steel platform.

Table 2: SLM processing parameters to process Diabraze

\begin{tabular}{l|c|c|c|c}
\hline & $\begin{array}{c}\text { Laser power } \\
\mathrm{P}_{\mathrm{L}}(\mathrm{W})\end{array}$ & $\begin{array}{c}\text { Layer thickness } \\
\mathrm{t}(\mu \mathrm{m})\end{array}$ & $\begin{array}{c}\text { Scan velocity } \\
\mathrm{v}_{\mathrm{s}}(\mathrm{mm} / \mathrm{s})\end{array}$ & $\begin{array}{c}\text { Hatch distance } \\
\mathrm{d}(\mathrm{mm})\end{array}$ \\
\hline Value / range & 100 & 30 & $100-1 ' 100$ & $0.08,0.1,0.12$ \\
\hline
\end{tabular}

Processing of Diabraze with 10 to 20 vol\% Ni-coated diamond particles

A DOE (Table 3) was performed with a selection of suitable processing parameters according to Table 2, producing $10 \times 10 \times 7 \mathrm{~mm}^{3}$ test cubes. Processing was performed in protective atmosphere using Argon.

Table 3: SLM processing parameters to process Diabraze with 10 vol\% and 20 vol\% Ni-coated diamond

\begin{tabular}{l|c|c|c|c}
\hline & $\begin{array}{c}\text { Laser power } \\
\mathrm{P}_{\mathrm{L}}(\mathrm{W})\end{array}$ & $\begin{array}{c}\text { Layer thickness } \\
\mathrm{t}(\mu \mathrm{m})\end{array}$ & $\begin{array}{c}\text { Scan velocity } \\
\mathrm{v}_{\mathrm{s}}(\mathrm{mm} / \mathrm{s})\end{array}$ & $\begin{array}{c}\text { Hatch distance } \\
\mathrm{d}(\mathrm{mm})\end{array}$ \\
\hline Value / range & 100 & 30 & $700-1^{\prime} 100$ & $0.09,0.1,0.11$ \\
\hline
\end{tabular}

Sample Characterization

For scanning electron microscopic (SEM) analysis, selected specimens were prepared by crosssection cutting using an

Accutom automatic precision cut-off machine (Struers) at low force and 3,000 rpm. For detailed analysis, cross-section Ar ion milling was applied on the cutting surfaces of the free-standing parts using an IM4000 (Hitachi). This preparation removes contamination and smearing effects from mechanical cutting operation and produces clear cross-sections of the embedded diamonds. For SEM characterization, an XL-30 ESEM-FEG (Philips) equipped with SE and BSE detectors was used at an accelerating voltage of $20 \mathrm{kV}$. The phase analysis using X-ray diffraction (XRD) was performed on the top surface of the specimens using a Bruker D8 DISCOVER with $\mathrm{Cu} \mathrm{K}$ radiation. 


\section{Results and discussion}

Density and microstructure of the matrix material Diabraze alone

A high material density in the range of _95 per cent can be achieved with the development of an appropriate laser energy input and processing strategy (Figure 3).

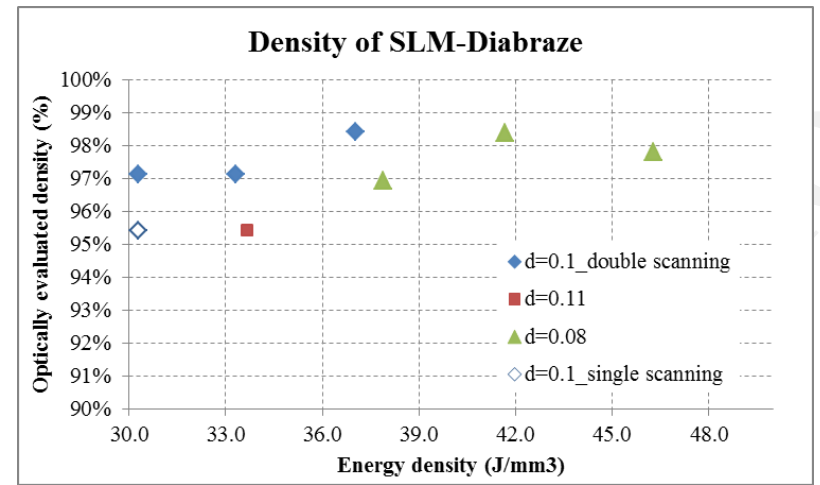

Figure 3: Optically evaluated density of SLM-processed Diabraze matrix material

The density was measured based on the analysis of the black content (corresponding to the pores) of micrographs using the ImageJ software. The quality of the created builds depends highly on the applied laser energy density. Best density was achieved with an energy input in the range of $E_{L}=42 \mathrm{~J} / \mathrm{mm}^{3}$, a hatch distance of $0.08 \mathrm{~mm}$ and single-scanning. Applying double-scanning with an energy input of $\mathrm{E}_{\mathrm{L}}$ $=33 \mathrm{~J} / \mathrm{mm}^{3}$ to $37 \mathrm{~J} / \mathrm{mm}^{3}$ and a hatch distance of $0.1 \mathrm{~mm}$ increased the density significantly, but resulted also in heat concentration effects in the part's corners (Figure 4).

However, although quite high material density is achievable, the material tends to crack with crack orientation along the build direction (z-axis), as shown in Figure 5. The results shown in Figure 3 and Figure 5 indicate a clear positive effect of the double-scanning procedure on the density and the occurrence of cracks. A density increase in the range of about 1.5 to 2 per cent was achieved (Figure 3 ). On the other hand, the related increased energy input leads to unwanted heat concentration effects, especially at locations with a reduced heat dissipation (corners, Figure 4 left), which might also be negative for the diamond particles (graphitization). For this reason, the single-scanning procedure was applied for the processing of Diabraze with diamonds (Figure 6).

Diabraze samples with embedded diamond particles

Figure 7 shows the SEM micrographs of the Diabraze samples with 10 volume per cent Ni-coated diamond particles processed with an energy input $\mathrm{E}_{\mathrm{L}}=40.4 \mathrm{~J} / \mathrm{mm}^{3}$ and $\mathrm{E}_{\mathrm{L}}=50.5 \mathrm{~J} / \mathrm{mm}^{3}$, respectively.
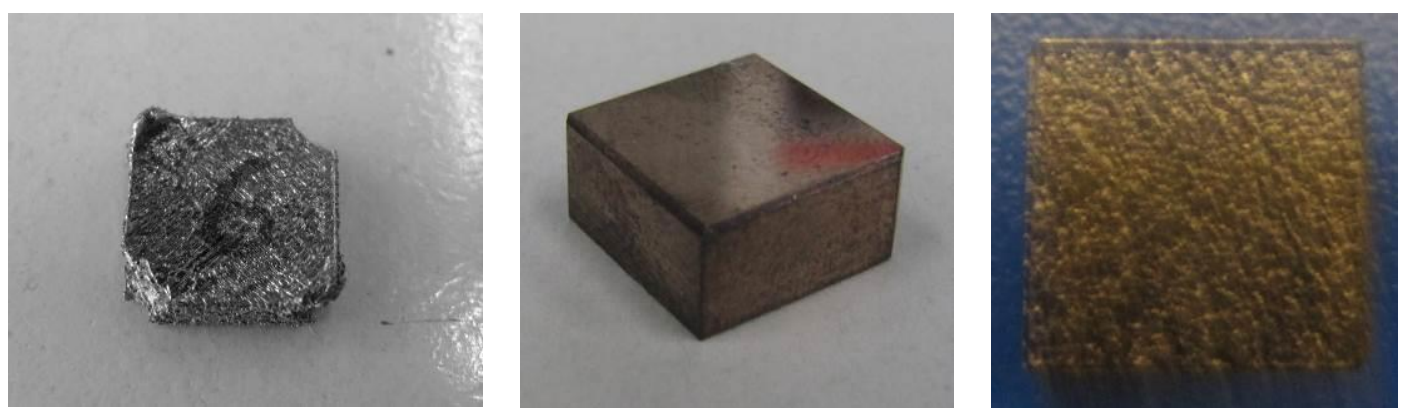

Figure 4: Diabraze samples. Bad sample produced with double scanning (left); good sample processed with $\mathrm{P}_{\mathrm{L}}=100 \mathrm{~W}, \mathrm{~d}=0.11 \mathrm{~mm}$ and $\mathrm{v}_{\mathrm{s}}=900^{\mathrm{mm}} / \mathrm{s}$ (centre, right) 

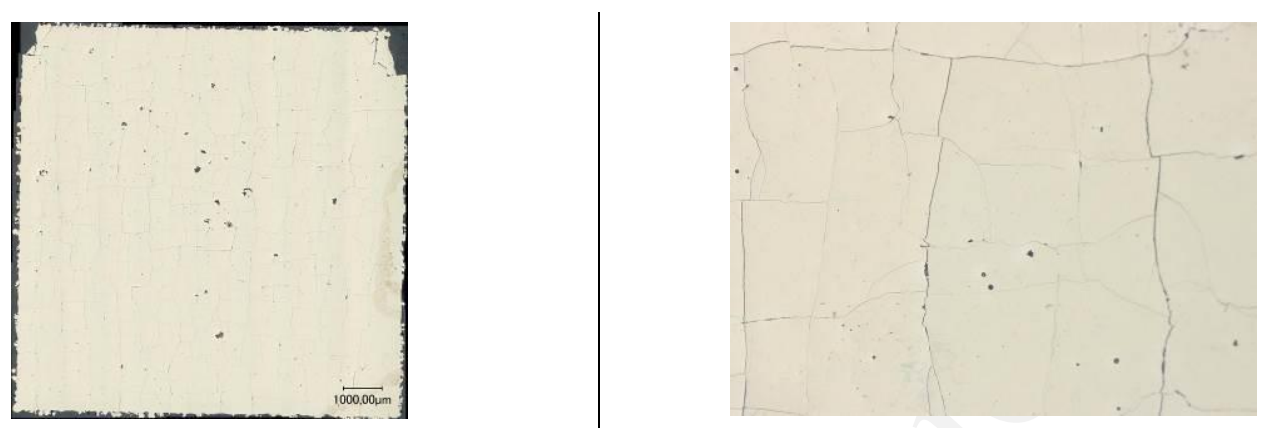

Energy input $\mathrm{E}_{\mathrm{L}}=30.3 \mathrm{~J} / \mathrm{mm} 3$, single scanning, $\mathrm{d}=0.1 \mathrm{~mm}$

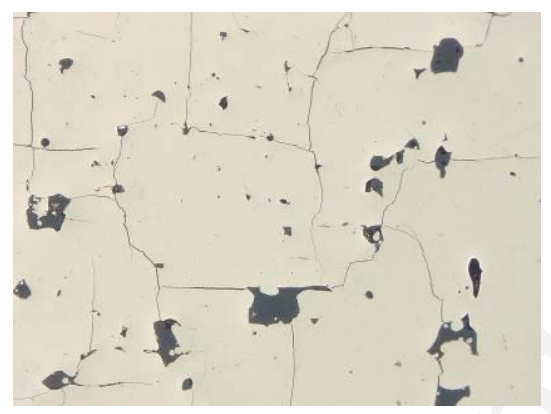

Energy input $\mathrm{E}_{\mathrm{L}}=30.3 \mathrm{~J} / \mathrm{mm} 3$, double scanning, $\mathrm{d}=$ $0.1 \mathrm{~mm}$

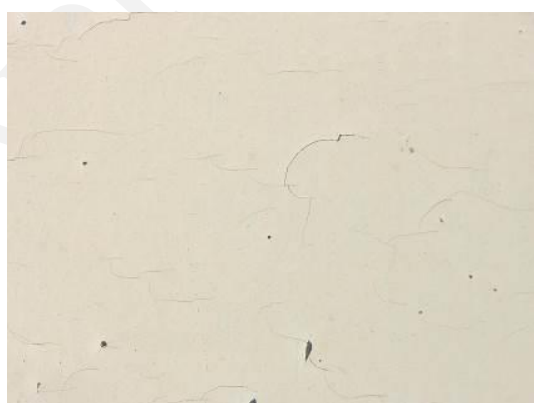

Figure 5: Cross-sections of Diabraze samples with different specific energy input $\mathrm{E}_{\mathrm{L}}$, double and single scanning, but the same hatch distance $\mathrm{d}$.

Some residual porosity as well as cracks are visible in the matrix of both samples. Compared to the results of the brazing alloy without diamond particles at $\mathrm{E}_{\mathrm{L}}=40.4 \mathrm{~J} / \mathrm{mm}^{3}$ (Figure 7, left), this porosity is somewhat higher. It is expected that this is a result of the effect of the Ni coating, which acts as an additional heat think, thereby reducing the energy available for the matrix. Therefore, the energy input required for a same material density as without diamond particles is increased.
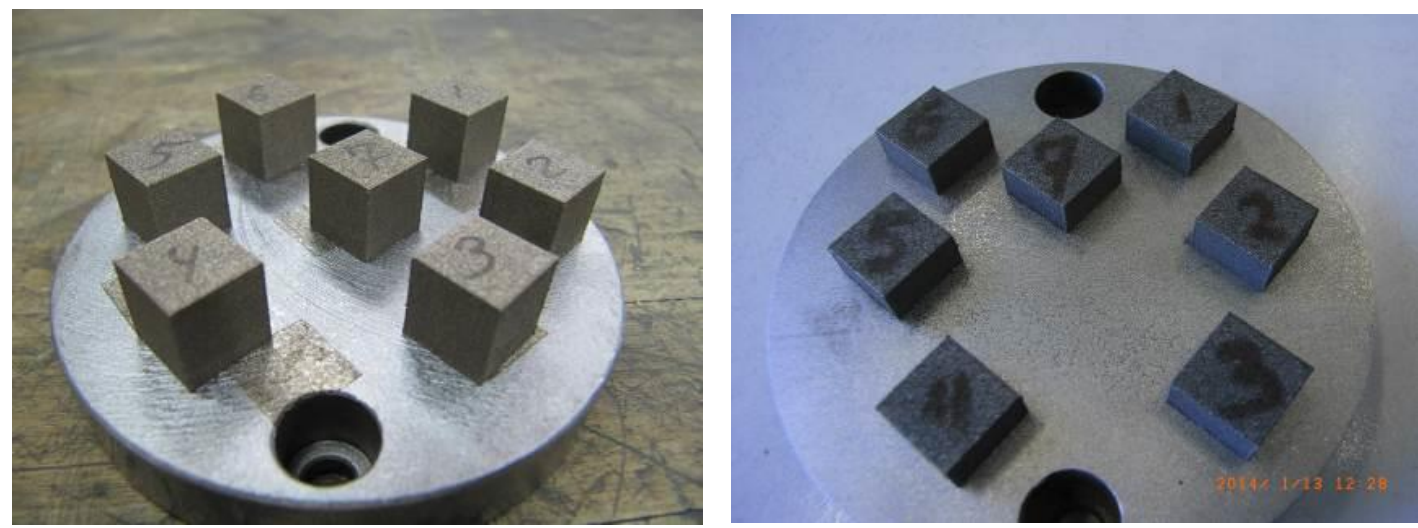

Figure 6: SLM-samples of Diabraze with 10 vol\% diamond (left) and 20 vol\% Ni-coated diamond (right)

The bright horizontal lines in Figure 7 are an artefact from the mechanical cutting process. Lines radiating from the top surface of the specimens are caused by the ion cross-section milling. The dark dots represent the diamonds, which are homogeneously distributed in the matrix. Obviously, the majority of the diamonds survived the SLM process almost unchanged. The microstructures of the Diabraze samples with 20 volume per cent Ni-coated diamond look similar to the ones containing 10 volume per cent diamond, although more and larger pores in comparison with the 10 volume per cent samples are visible (compare Figures 7 and 8). 

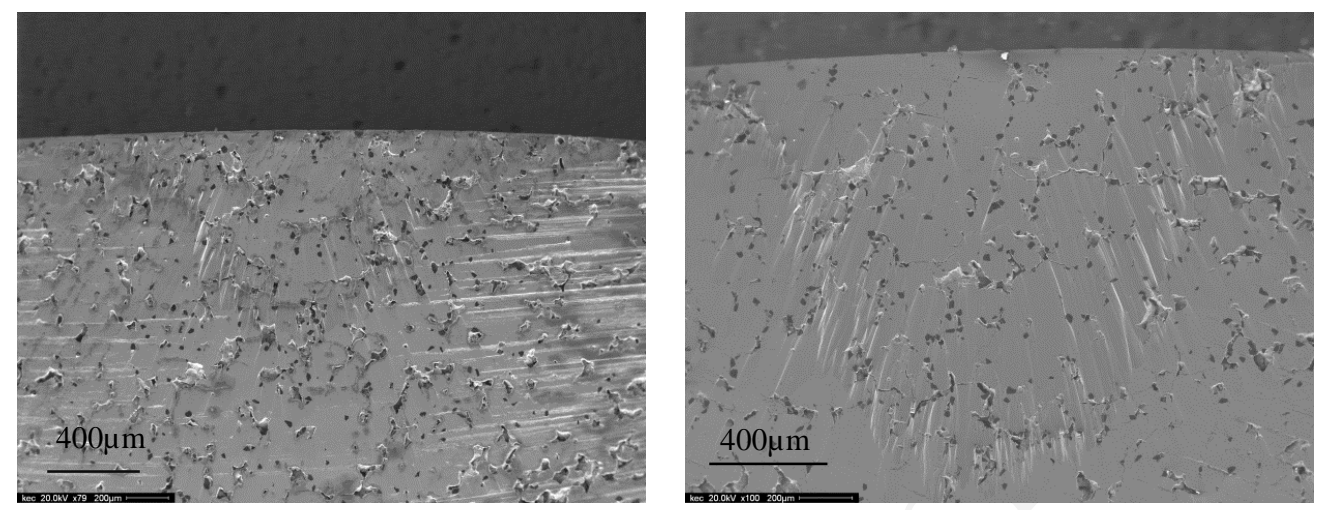

Figure 7: SEM (SE) - Micrographs of SLM-samples of Diabraze with 10 vol\% Ni-coated diamond, energy input $\mathrm{E}_{\mathrm{L}}=40.4 \mathrm{~J} / \mathrm{mm}$ (left) and $\mathrm{E}_{\mathrm{L}}=50.5 \mathrm{~J} / \mathrm{mm} 3$ (right).
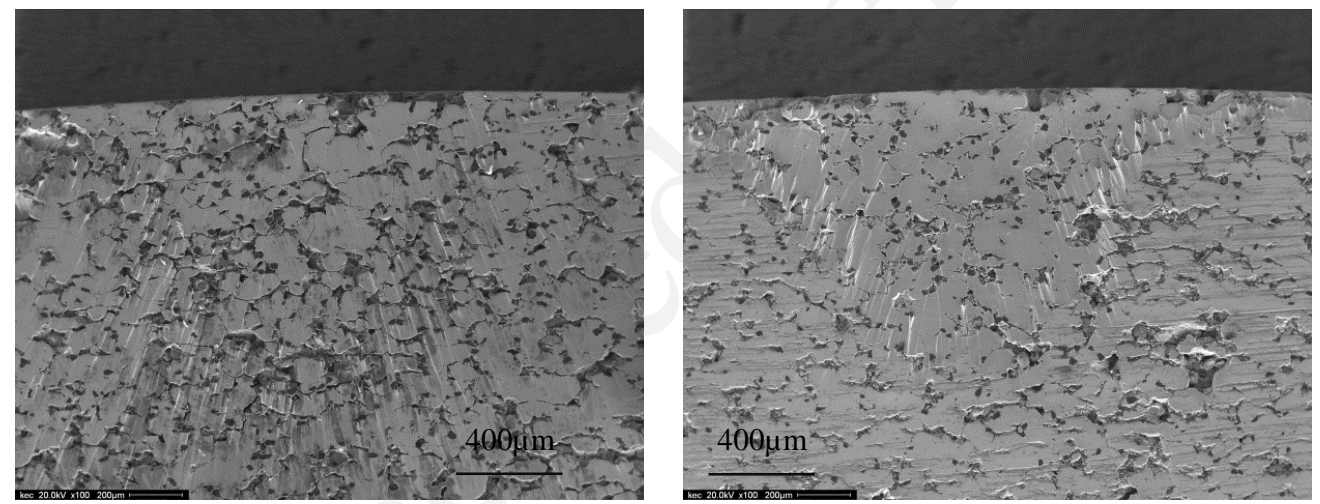

Figure 8: SEM (SE) - Micrographs of SLM-samples of Diabraze with 20 vol\% diamond, energy input $\mathrm{E}_{\mathrm{L}}=30.3$ $\mathrm{J} / \mathrm{mm} 3$ (left) and $\mathrm{E}_{\mathrm{L}}=41.2 \mathrm{~J} / \mathrm{mm} 3$ (right).

Figure 9 shows the SEM-BSE micrographs of the 10 and 20 volume per cent samples at a lower energy input EL. The diamonds are fully embedded in the $\mathrm{Cu}-\mathrm{Sn}-\mathrm{Ti}-\mathrm{Zr}$ matrix. In the left figure, cracks that have formed in the vicinity of the diamonds as well as unmolten powder particles are visible. The Ni coating of the diamonds seems to have completely dissolved in Diabraze during the SLM process. In both figures, a greyish phase which either appears as small dots or as elongated lines can be seen in the matrix between the diamonds (Figure 9).
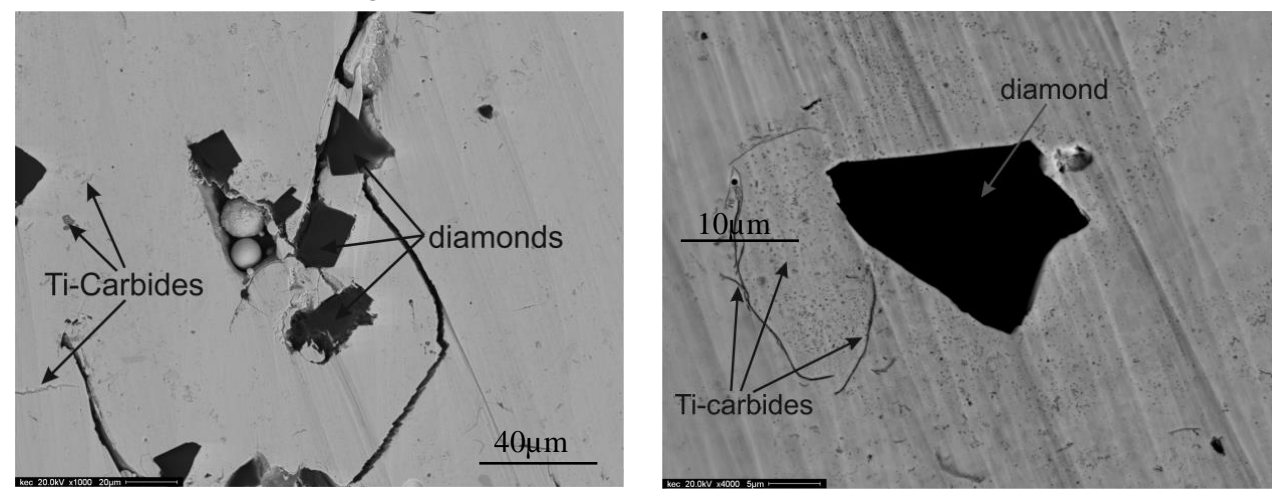

Figure 9: SEM (BSE) - micrographs; Diabraze with 10Vol\% Diamond, embedded diamonds with cracks in the matrix (left); Diabraze with 20Vol\% Diamond; intact diamond embedded in the matrix surrounded by $\mathrm{TiC}$ particles (right)

It is assumed that these are Ti carbides that have formed due to the reaction of the Ti from the matrix material with the carbon from the diamonds. The outer part of the diamonds obviously partly dissolves in the matrix during the SLM process. Previous studies of Klotz et al. (2008) of the interface reactions during brazing of diamonds with Diabraze have shown that a TiC reaction layer with a thickness between 60 and $150 \mathrm{~nm}$ forms at the interface between the diamond and the matrix. However, no clear 
reaction layer could be observed in the SLM samples so far. Due to the presence of the Ni coating on the diamonds and due to the very short interaction times of the diamond particles with the liquid alloy, it is assumed that only a very thin TiC layer might have formed which cannot be seen in the SEM.

Figure 9 clearly shows that the diamonds remained in the matrix after SLM processing, which is also indicated by the small peaks in the XRD spectra (Figure 10). The XRD spectra also indicates that the matrix consists of a mixture of a $\mathrm{Cu}$ in solid solution and $(\mathrm{Cu}, \mathrm{Sn})_{3} \mathrm{Ti}_{5}$ with $\mathrm{Cu}$ as the main phase.

Some smaller peaks representing TiC $(\diamond)$ could be identified. These peaks were more pronounced in the samples containing 20 volume per cent diamond, indicating that more $\mathrm{TiC}$ has been formed (indicated in Figure 9). The results confirm the observations from the SEM investigations mentioned above. Ni could not be observed in the XRD spectra due to the very low Ni content, which is below the detection limit. However, Ni could be detected in the matrix by an additional energy-dispersive X-ray spectroscopic (EDX) analysis.

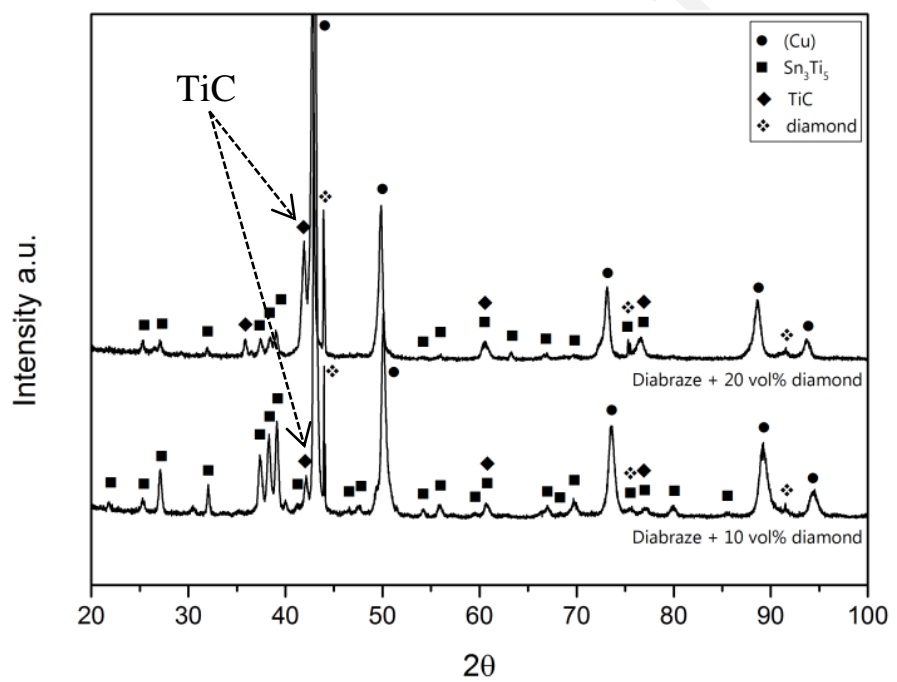

Figure 10: XRD-spectra of Diabraze with 10 vol\% Diamond (bottom) and 20 vol\% Diamond (top). The identified phases are indicated.

\section{Conclusions}

From this feasibility study on the processing of an active brazing alloy with incorporated Ni-coated diamond particles, the following main conclusions can be taken.

- It is principally possible to process a $\mathrm{Cu}-\mathrm{Sn}-\mathrm{Ti}-\mathrm{Zr}$ active brazing alloy with $\mathrm{SLM}$, reaching a high material density. However, the used alloy chemistry is not yet optimized for a use in the SLM process, where significant internal stresses are known to arise, as pointed out by e.g. Kruth et.al. (2012) and Cloots et.al. (2013).

Consequently, due to the brittle material behaviour cracking phenomena occur. Therefore, a lower Ti-content would be beneficial, leading to a more ductile matrix material with a correspondingly lower cracking tendency.

- The cyclic heat impact on the diamond particles, which is a result of the layer-wise SLM build process, does not lead to their graphitization. This is a result of the comparably low melting temperature of the active brazing alloy and its high thermal conductivity, which limits the heat impact significantly.

- The diamond particles are well bonded to the matrix material, most probably by the formation of a very thin TiC-layer around the diamond particles. This however is not yet approved and needs further analysis. 
The Ni-coating is fully dissolved in the matrix material, which has been confirmed by EDX measurements. We expect that the Ni-coating acts as an additional thermal prevention of the diamond particles (thermal heat shield).

\section{Outlook}

These basic observations encourage the use and further development of additively manufactured tooling materials with incorporated diamond particles. An assessment will be performed to qualify the abrasive properties of the SLM built tooling material against conventional grinding tools. Furthermore, as the matrix material is not yet optimized with regard to the incorporated hard phases (diamonds) and the SLM process, specific material development is needed to improve the material performance.

\section{Literature}

Averyanova, M. and Bertrand, P. (2010), "Direct manufacturing of dense parts from martensitic precipitation hardening steel gas atomized powder by selective laser melting (SLM) technology", International Conference on Advanced Research in Virtual and Rapid Prototyping, CRC Press/Balkema, Leiria, Portugal, 6-10 October, pp. 343-348.

Berkau, A. (2011), "Einsatzmöglichkeiten des Strahlschmelzens zur Herstellung von Bauteilen aus Aluminium”, Anwenderforum Rapid Product Development, 5 Oktober, Stuttgart. Brandl, E., Heckenberger, U., Holzinger, V. and Buchbinder, D. (2012), "Additive manufactured AlSi10Mg samples using Selective Laser Melting (SLM): microstructure, high cycle fatigue, and fracture behavior", Materials \& Design, Vol. 34, pp. 159-169.

Buchbinder, D., Schleifenbaum, H., Heidrich, S., Meinersb, W. and Bültmannc, J. (2011), "High power selective laser melting (HP SLM) of aluminum parts", Lasers in Manufacturing 2011 - Proceedings of the Sixth International WLT Conference on Lasers in Manufacturing, Vol. 12, pp. 271-278.

Buhl, S., Leinenbach, C., Spolenak, R. and Wegener, K. (2012), "Microstructure, residual stresses and shear strength of diamond-steel-joints brazed with a Cu-Sn-based active filler alloy", International Journal of Refractory Metals and Hard Materials, Vol. 30 No. 1, pp. 16-24.

Cloots, M., Spierings, A. and Wegener, K. (2013), Thermomechanisches Multilayer-Modell zur Simulation von Eigenspannungen in SLM-Proben, Sysweld User Forum, Weimar.

Ding, W.-F., Zhu, Y.J., Xu, J.H. and Su, H.H. (2013), "Interface characteristics and fracture behavior of brazed polycrystalline CBN grains using Cu-Sn-Ti alloy”, Materials Science and Engineering: A, Vol. 559, pp. 629-634.

Klotz, U.E., Liu, C., Khalid, F.A. and Elsener, H.-R. (2008), "Influence of brazing parameters and alloy composition on interface morphology of brazed diamond”, Materials Science and Engineering: A, Vol. 495 Nos 1/2, pp. 265-270.

Kovalenko, V., Golovko, L., Meijer, J. and Anyakin, M. (2007), "New developments in laser sintering of diamond cutting disks", CIRP Annals - Manufacturing Technology, Vol. 56 No. 1, pp. 189-192.

Kruth, J.P., Deckers, J., Yasa, E. and Wauthlé, R. (2012), “Assessing and comparing influencing factors of residual stresses in selective laser melting using a novel analysis method", Journal of Engineering Manufacture, Vol. 226 No. 6, pp. 980-991.

Kupferinstitut, C.A.-D. (2005), Material Datasheet on CuSn12-C (2.1052), D. Kuperinstitut, Düsseldorf.

Mumtaz, K.A., Erasenthiran, P. and Hopkinson, N. (2008), "High density selective laser melting of Waspaloy®", Journal of Materials Processing Technology, Vol. 195 Nos 1/3, pp. 77-87.

Murr, L.E., Quinones, S.A., Gayton, S.M., Lopez, M.I., Rodela, A., Martinez, E.Y., Hernandez, D.H. and Medina, F. (2009), "Microstructure and mechanical behavior of Ti-6Al-4V produced by rapid-layer manufacturing, for biomedical applications", Journal of the Mechanical Behavior of Biomedical Materials, Vol. 2 No. 1, pp. 20-32.

Rabinkin, A., Shapiro, A.E. and Boretius, M. (2013), “6 - Brazing of diamonds and cubic boron nitride”, in Sekulic', D.P. (Ed.), Advances in Brazing, Woodhead Publishing, pp. 160-193.

Richardson, A.F., Neville, A. and Wilson, J.I.B. (2003), "Developing diamond MMCs to improve durability in aggressive abrasive conditions", Wear, Vol. 255 Nos 1/6, pp. 593-605. 
Rickenbacher, L., Etter, T., Hövel, S. and Wegener, K. (2013), "High temperature material properties of IN738LC processed by Selective Laser Melting (SLM) technology", Rapid Prototyping Journal, Vol. 19 No. 4, pp. 282-290.

Spierings, A.B., Herres, N. and Levy, G. (2011), "Influence of the particle size distribution on surface quality and mechanical properties in additive manufactured stainless steel parts", Rapid Prototyping Journal, Vol. 17 No. 3, pp. 195-202.

Wang, J., Liu, C., Leinenbach, C., Klioz, U., Uggowitzer, P.J. and Loffer, J.F. (2011), "Experimental investigation and thermodynamic assessment of the $\mathrm{Cu}-\mathrm{Sn}-\mathrm{Ti}$ ternary system”, Calphad, Vol. 35 No. 1, pp. 82-94.

\section{Corresponding author}

Adriaan Bernardus Spierings can be contacted at: spierings@inspire.ethz.ch 